\title{
AS ONDAS DE FRIO E SUA INFLUÊNCIA NA SAÚDE PÚBLICA DO PONTAL DO TRIÂNGULO MINEIRO, MINAS GERAIS, BRASIL
}

\author{
COSTA, Rildo Aparecido - rildocosta@ufu.br \\ Universidade Federal de Uberlândia - Campus Pontal / UFU
}

\begin{abstract}
RESUMO: Desde os tempos antigos, os seres humanos relacionam a sucessão de tipos de tempos climáticos com a saúde humana. Essa junção torna-se visível, quando os indivíduos sofrem com eventos extremos, tais como calor intenso, temperaturas baixas, umidade baixa ou variações bruscas diárias dos mesmos, influenciando assim, no surgimento de alguns sintomas, tais como, dores de cabeça, arritmias cardíacas, inchaço dos membros inferiores, agravamento de problemas respiratórios, irritações nos olhos, dentre outras enfermidades. Este trabalho tem como objetivo principal analisar a ocorrência de Ondas de Frio e sua influência no número de internações por infarto agudo do miocárdio na região do Pontal do Triângulo Mineiro, MG. Para tanto, foram utilizados dados de seis estações automáticas, em um intervalo de 10 anos (2008 a 2017). Para determinar as Ondas de Frio, utilizou-se o percentil 5 como parâmetro e os dados de internações foram adquiridos junto às Secretarias Municipais de Saúde. Observou-se, na região do Pontal do Triângulo Mineiro a ocorrência de quatro ondas de frio de grande intensidade, onde se destacou duas no mês de maio e duas no mês de julho, ocasionando um aumento no índice de internação de mais de $100 \%$ durante a ocorrência das ondas de frio.
\end{abstract}

PALAVRAS-ChAVe: Ondas de frio, Climatologia Médica, Morbidade, Doenças circulatórias, Saúde Pública.

THE COLD WAVES AND THEIR INFLUENCE ON THE PUBLIC HEALTH OF THE TRIÂNGULO PONTAL MINEIRO, MINAS GERAIS, BRAZIL

\begin{abstract}
Since ancient times, humans have related the succession of types of climatic times to human health. This junction becomes visible when individuals suffer from extreme events such as intense heat, low temperatures, low humidity or sudden daily variations of them, thus influencing the onset of some symptoms such as headaches, cardiac arrhythmias, swelling of the lower limbs, aggravation of respiratory problems, eye irritations, among other diseases. This work has as main objective to analyze the occurrence of Cold Waves and their influence on the number of hospitalizations due to acute myocardial infarction in the region of Pontal do Triângulo Mineiro, MG. For this, data from six automatic stations were used, in a 10-year interval (2008 to 2017). In order to determine the Cold Waves, the percentile 5 was used as parameter and the data of hospitalizations were acquired with the Municipal Health Secretaries. In the region of Pontal do Triângulo Mineiro the occurrence of four waves of intense cold, where two were highlighted in the month of May and two in the month of July, causing an increase in hospitalization rate of more than $100 \%$ during the occurrence of cold waves.
\end{abstract}

KEYWORDS: Cold waves, Medical Climatology, Morbidity, Circulatory diseases, Public Health.

LAS ONDAS DE FRIO Y SU INFLUENCIA EN LA SALUD PÚBLICA DEL PONTAL DEL TRIÂNGULO MINEIRO, MINAS GERAIS, BRASIL

RESUMEN: Desde los tiempos antiguos, los seres humanos relacionan la sucesión de tipos de tiempos climáticos con la salud humana. Esta unión se hace visible cuando los individuos sufren eventos extremos tales como calor intenso, temperaturas bajas, humedad baja o variaciones bruscas diarias de los mismos, influenciando así, en el surgimiento de algunos síntomas, tales como dolores de cabeza, arritmias cardíacas, hinchazón de los miembros inferiores, agravamiento de problemas respiratorios, irritaciones en los ojos, entre otras enfermedades. Este trabajo tiene como objetivo principal analizar la ocurrencia de Ondas de Frío y su influencia en el número de internaciones por infarto agudo del miocardio en la región del Pontal del Triángulo Mineiro, MG. Para ello, se utilizaron datos de seis estaciones automáticas, en un intervalo 
de 10 años (2008 a 2017). Para determinar las Ondas de Frío, se utilizó el percentil 5 como parámetro y los datos de internaciones fueron adquiridos junto a las Secretarías Municipales de Salud. Se observó, en la región del Pontal del Triángulo Mineiro, la ocurrencia de cuatro olas de frío de gran intensidad, donde se destacó dos en el mes de mayo y dos en el mes de julio, ocasionando un aumento en el índice de internación de más del $100 \%$ durante la ocurrencia de las olas de frío.

PALABRAS CLAVe: Ondas de frío, Climatología Médica, Morbilidad, Enfermedades circulatorias, Salud Pública.

\section{INTRODUÇÃO}

A sucessão dos tipos de tempo atmosférico é relacionada à saúde humana desde os primórdios. Os indivíduos eram acometidos pelas variações climáticas extremas, que nos dias atuais são conhecidas como eventos extremos, sendo neste trabalho, considerados como algo inesperado, fora do ritmo climático.

Calor intenso, temperaturas baixas, umidade baixa ou variações bruscas diárias são alguns dos exemplos de eventos extremos que ocorrem pelo mundo. Esses eventos fazem agravar ou surgir alguns sintomas como dores de cabeça, arritmias cardíacas, inchaço de membros inferiores, agravamento de problemas respiratórios, irritação nos olhos, dentre outras enfermidades.

Estes males que se agravam com os eventos extremos são efeitos manifestos de como o ritmo climático pode influenciar na saúde da população em geral, porém, as populações mais vulneráveis são acometidas com maior intensidade. Com o decorrer dos anos, os cientistas começaram a perceber que não se poderia explicar a doença somente pela doença em si, sendo necessário compreender a relação dos tipos de tempo atmosférico com este intricado processo.

Embora a complexa relação saúde e eventos atmosféricos tenha sido observada desde os tempos antigos, a ciência nem sempre se interessou totalmente por este assunto. Contudo, nas últimas décadas, esse interesse tomou corpo, principalmente com o avanço do conhecimento das ciências naturais e sua relação com a ciência da saúde. Além da evolução de conceitos, metodologias e principalmente da tecnologia, possibilitou mudanças na maneira de se estudar o ambiente atmosférico e sua influência na saúde.

Diante deste cenário, a Climatologia Médica, integrante dos estudos referentes à Geografia Médica, começa a se destacar no cenário científico por desenvolver suas pesquisas na interface entre a Epidemiologia, a Geografia, Meteorologia e a Biologia. Isto ocorre, porque a saúde é derivada "do resultado de complexas e dinâmicas inter-relações entre o homem e o meio, o estilo de vida, o meio ambiente (físico e social), a biologia humana e os serviços de atenção à saúde" (SOUZA; SANT'ANNA NETO, 2008, p. 119). Portanto, a Climatologia Médica dedica-se, à compreensão da sucessão de ritmos de tempo climático e influência nos indivíduos, ou seja, "trabalha a relação saúde/doença e tempo/clima" (SARTORI, 2014, p. 16).

As relações existentes entre os diferentes tipos de tempo atmosférico e a saúde humana são complexas, pois dependem de vários processos, dentre eles podem-se destacar a intensidade, duração e variação abrupta do tempo 
atmosférico. Vale destacar, que outro fator importante a ser levado em consideração nesta análise, é a sensibilidade de cada indivíduo.

Existem dois aspectos básicos da influência climática na doença e na saúde humana: a relação dos fatores climáticos com organismos doentes ou seus portadores e, os efeitos do tempo e clima na resistência do corpo. As condições de tempo por si só não provocam as enfermidades. Porém, é notório o agravamento dessas doenças, principalmente, em pessoas mais debilitadas e vulneráveis sendo estas, geralmente idosos e crianças. O funcionamento do corpo, na maioria das vezes, responde negativamente quando há uma variação dos tipos de tempo, principalmente quando há uma amplitude (térmica ou higrométrica) diária significativa (SARTORI, 2014).

Dentre os estudos que a Climatologia Médica se debruça, destacam-se aqueles que tratam sobre as temperaturas e sua relação com o cotidiano das pessoas. As temperaturas extremas influenciam diretamente na saúde humana, conforme pesquisas realizadas neste âmbito, analisaram. Silva (2010) verificou que os processos fisiológicos de termorregulação e regulação circulatória dos indivíduos, são dependentes da temperatura do ambiente atmosférico.

As temperaturas extremas baixas são capazes de afetar a saúde dos seres humanos, pois ocorre o processo de vasoconstrição, ou seja, a contração das veias que são responsáveis pela circulação do sangue no organismo. Deste modo, "um dia com temperaturas baixas podem aumentar as chances das veias coronárias sofrerem com espasmos. Por isso, na temporada de frio, os casos de enfarte aumentam até 30\%"(SARTORI, 2014, p.38).

Estas temperaturas mínimas, permanecendo por mais de três dias, podem se configurar como ondas de frio, que afetam demasiadamente a população de um determinado local, podendo agravar sua saúde. Isto dependerá também, do grau de vulnerabilidade que cada pessoa estará exposta.

As ondas de frio aliadas a uma umidade relativa do ar baixa, podem contribuir para o agravamento das doenças cardiorrespiratórias, pois as inflamações se tornam mais freqüentes, comprometendo assim, o bom funcionamento do coração e sistema respiratório. Quando o corpo humano está debilitado, o indivíduo estará vulnerável a este processo.

As morbidades cardiovasculares são significativas quando se estuda a influência do tempo na saúde do ser humano. Segundo dados da OMS (Organização Mundial da Saúde) as doenças cardiovasculares (como o Infarto Agudo do Miocárdio -IAM e o Acidente Vascular Cerebral - AVC) lideram o ranking das mortes no mundo. Em 2011, aproximadamente 17 milhões de pessoas foram vitimadas por este problema. Embora, seja inegável a influência do clima na saúde destes indivíduos, nem todas as mortes são derivadas e agravadas pelos tipos de tempo climático.

Portanto, a proposta da presente pesquisa foi compreender como as ondas de frio influenciaram no agravamento do Infarto Agudo do Miocárdio. A região do Pontal do Triângulo Mineiro foi escolhida como a área de estudo. Vale destacar que a delimitação regional aqui denominada como Pontal do Triângulo Mineiro, refere-se a um conjunto de municípios pertencentes à microrregião de Ituiutaba e a microrregião de Frutal, contando com dezoito municípios e uma população aproximada de 322.400 habitantes (IBGE, 2010). A figura 1, mostra a localização da referida região. 


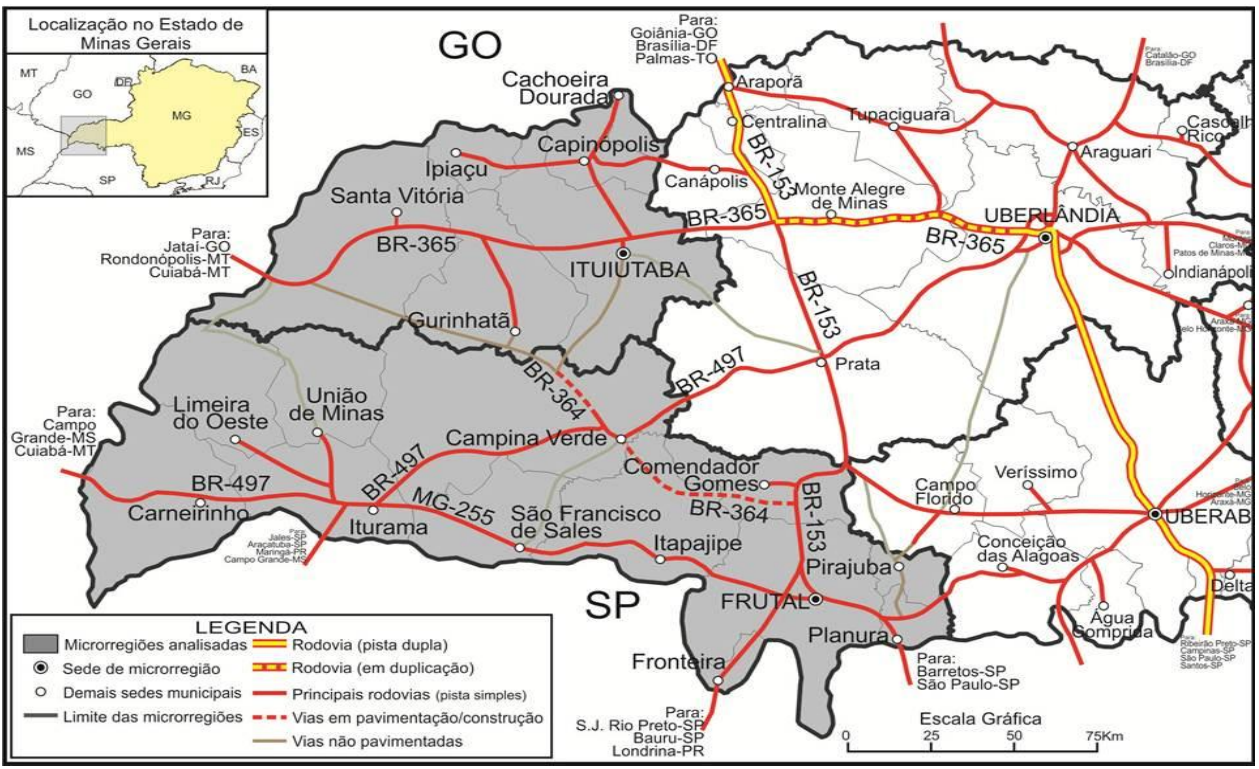

Figura 1 - Pontal do Triângulo Mineiro: localização.Fonte: Miyazaki (2018).

Essa região está localizada nas chapadas e chapadões do Triângulo Mineiro e Alto Paranaíba, entre os rios Grande e Paranaíba (AB'SÁBER, 1977), com altitudes variando entre 370 a $620 \mathrm{~m}$ de altitude. Está sob a influência, de forma geral, da dinâmica das Massas de Ar Polar, que é responsável pela entrada de frentes frias e da Massa Equatorial Continental, responsável pela distribuição da umidade na região.

De acordo com Mendes e Queiroz(2011, p.337), o verão é caracterizado por sucessões de dias com temperaturas elevadas, que tem a influência da massa tropical atlântica continentalizada (mTac), e dias com temperaturas amenas (inverno) causado pela ação da massa polar atlântica (mPa). Há também significativa escassez de umidade e precipitação. Desta forma, o Pontal do Triângulo apresenta o clima tropical com duas estações bem definidas, 0 verão chuvoso e com temperaturas elevadas e o inverno com escassez de chuvas e temperaturas amenas (MENDES; QUEIROZ, 2011, p. 336).

No inverno, quando a atuação da Massa Polar Atlântica ocorre de forma mais continental, os vales dos rios servem de corredores para essa massa polar, fazendo com que a região se resfrie ocasionando as ondas de frio, principalmente devido a sua intensidade. Portanto, uma região que possui quase sempre temperaturas altas, acaba sentindo uma queda brusca da temperatura.

\section{UMA ABORDAGEM SOBRE CLIMATOLOGIA MÉdICA E OS TIPOS DE TEMPO ATMOSFÉRICO}

As discussões acerca dos processos determinantes da relação saúde/doença, inevitavelmente perpassam pelo ambiente em que o homem ocupa e evolui. Um desses elementos do ambiente é o tempo e, mais amplamente, o clima, que afetam direta e indiretamente os mecanismos reguladores corporais, ou seja, a homeostasia, que tem como função primordial manter o equilíbrio das funções orgânicas. A saúde é considerada, portanto, 
"como um estado de completo bem-estar, físico e mental" (HEINLEIN, 2011, p. 12 ), sendo resultado das interações internas (do organismo) com o meio que o circunda.

As influências dos mecanismos climáticos, principalmente as alterações das propriedades físicas e químicas do ambiente sobre a saúde, mostraram-se consecutivamente, intensas. Essa preocupação já se fazia presente no século $\mathrm{V}$ a. C, e nos dizeres de Hipócrates, "Não ignore o que diz respeito ao estado do tempo, porque tudo o que o diz respeito está intimamente relacionada com a medicina".

Hipócrates foi um dos principais estudiosos dos impactos do ambiente no homem, afirmava que "as diferenças geográficas resultavam em diferentes padrões de doenças, mas alguns elementos geográficos eram mais valorizados, tais como o clima, a vegetação e a hidrografia" (RIBEIRO, 2004, p. 72). Foi a partir de seus estudos que nasce o determinismo ambiental e que, segundo PASCOALINO (2013, p. 37) "formaram as bases das teorias higienistas e sanitaristas com ênfase nos fatores ambientais".

A forma de contágio de uma gama de doenças não era compreendida pela sociedade ao longo de vários séculos. Outro fator desconhecido, era como estas se disseminavam pelo espaço geográfico, por isso, o determinismo ambiental tomou tanto corpo, principalmente em relaçãoàs doenças que eram atribuídas às condições do tempo atmosférico. Destacar o lugar como agente responsável pela condição da saúde e da doença, fez com que os estudos da medicina avançassem no tempo e no espaço, criando conceitos e teorias. Essas relações entre o espaço geográfico, o saudável e o patológico foram um dos marcos para a criação da chamada Geografia Médica.

A Geografia Médica tem seu início, enquanto ciência, quando se começa a evoluir o conhecimento médico a respeito das enfermidades, das "maneiras com que eram tratados os homens perante o meio em condições de saúde, doença e cura" (PASCOALINO, 2013, p. 57).

Na história, a Geografia Médica teve sua base fundamentada no pensamento hipocrático. A obra "Dos Ares, das Águas e dos Lugares", desenvolvida por Hipócrates e datada do século $V$ a. C., foi o ponto de partida para os estudos relacionados ao ambiente e sua influência na sociedade. Entretanto, determinar essa obra como fator primordial para o alicerce da Geografia Médica se faz de forma forçosa, pela imprecisão da mesma, pois como afirma Ferreira (1991, p. 303), "não podemos identificar estas obras, de conteúdo muito variado e análise pouco sistemática, à geografia científica tal como a conhecemos hoje". Não é possível, contudo, deixar de mencionar a importância desta obra para os estudos de Geografia Médica.

Neste período, não eram conhecidas as formas de transmissão das doenças. Idealizava-se sua propagação através da água, ar e sangue e seu controle se daria pela intervenção do homem no ambiente tornando-o estéril, dificultando assim, a disseminação de doenças. Estes preceitos foram denominados de Teoria do Higienismo.

Dessa forma, para Hipócrates, segundo Diniz (2006, p. 31) a pessoa sã "é a mistura equilibrada dos elementos constituintes do homem", por outro lado a doença seria "a separação e o isolamento de um dos constituintes do corpo humano em relação aos outros". A concepção de doença nesse pensamento é uma ruptura. Esse pensamento só foi possível graças à noção de physis, que foi 
aplicada às enfermidades, buscando interpretações pela razão e não mais pelos aspectos místicos e religiosos (PASCOALINO, 2013). Essa noção buscava a causa da enfermidade e o entendimento de sua fisiologia (DINIZ, 2006).

No século $\mathrm{V}$ a. C. a relação saúde-doença se destacava através de dois mitos, o primeiro era o mito de Hygeia, onde a doença era considerada como um "relacionamento inadequado com a natureza" e a recuperação estaria na higiene e em um modo de vida adequado do enfermo. O segundo, o mito de Asclépio, se baseava na total ausência de preocupação com o modo de vida do doente, criando uma medicina intervencionista e curativa (DINIZ, 2006, p. 25). Esse mesmo autor salienta que é no segundo mito, que surge a escola de medicina com métodos próprios e 'mágicos', que viria compor a medicina científica posteriormente.

Na visão de Hipócrates, a relação saúde-doença adivinha do equilíbrio do organismo, ou seja, a doença estava intimamente relacionada com os desequilíbrios orgânicos. Todavia, destacava-se também nesse mal funcionamento do corpo, fatores externos. Nestes fatores eram bem caracterizadas as estações do ano (sazonalidade climática) e as variações bruscas do tempo. Portanto, a restauração da saúde viria pela adequação das situações do cotidiano adotando-se um modo de vida que favoreceria a saúde.

A importância da relação saúde-doença preconizada pelo pensamento Hipocrático, foi um marco nos estudos médico-ambientais e, por conseguinte na Geografia Médica. Nestes preceitos, o doente era visto de forma inseparável do ambiente que o rodeava, "Quando se estuda uma doença, principalmente metaxênica, sob o ângulo da geografia médica, devemos considerar, ao lado do agente etiológico, do vector, do reservatório, do hospedeiro intermediário e do Homem suscetível, os fatores geográficos" (LACAZ; BARUZZI; SIQUEIRA JÚNIOR, 1972, p. 1), esses fatores se resumiam aos físicos (clima e hidrografia), sociais (densidade de população e qualidade de vida) e biológicos (parasitismo, doenças predominantes e grupos sanguíneos).

Pode-se ressaltar, deste modo, que a Geografia Médica é resultado da correlação da medicina com os estudos geográficos, mais específico com os estudos do ambiente, onde se dá a relação da sociedade com a natureza. Nessa relação que surge a doença. Portanto, a Geografia Médica tem como finalidade, os estudos da "distribuição e da prevalecia das doenças na superfície da Terra [...] que possam advir por influência dos mais variados fatores geográficos e humanos" (PESSOA, 1960, p.5).

Em áreas geográficas diferentes podem-se apresentar doenças iguais ou semelhantes, bem como a influência dos fatores geográficos na sua disseminação, a sazonalidade climática, os solos, a vegetação e a influência dos tipos e variações de tempo fazem parte dos estudos de Geografia Médica. Partindo dos princípios hipocráticos de que o homem é parte intrínseca da natureza, em que essa própria natureza age sobre o homem influenciando em sua saúde.

Hipócrates se destacou nos estudos de Geografia Médica por elencar a eliminação das causas místicas sobre as doenças, demonstrando assim, sua causa natural. A saúde era resultado de "equilíbrios de elementos da natureza, [...] por meio da combinação de quatro elementos - a terra, a água, o fogo e o ar - delineando suas propriedades: seco, úmido, quente e frio" (SANT'ANNA 
NETO; SOUZA, 2008, p. 119). A doença era causada pelo desequilíbrio destes elementos.

Os preceitos hipocráticos ficaram marcados por acreditarem na possibilidade de se conhecer a doença pelos sintomas, chegando assim à sua cura. Neste período, ainda não se tinha desenvolvido o conceito de contágio, portanto, acreditava-se que "As influências externas podiam produzir doenças apenas através do frio, calor, umidade ou secura" (MARTINS, 1997, p. 41).

A Geografia Médica entra na medicina quando pacientes passaram a ser questionados sobre os locais onde viviam, demonstrando assim, a real necessidade do estudo do ambiente onde se vive e sua relação com o processo de saúde-doença. A informação produzida foi utilizada para elaboração de diagnósticos, buscando inclusive à solução de mudança de moradia na tentativa de um clima mais propenso à cura da doença. Isso envolvia também a mudança de estilo de vida (PEITER, 2005).

Durante os séculos XVI e XVII, durante viagens feitas para colônias Asiáticas, Africanas e Americanas, médicos anotaram em seus escritos sobre essas localidades visitadas, destacando os lugares, as doenças que os tinham afligido, os métodos locais de tratamento e o conhecimento sobre sua causa. Esses relatos ficaram conhecidos como Levantamento Médico Geográfico (ARMSTRONG, 1983).

Neste período, vários outros levantamentos foram desenvolvidos, principalmente por naturalistas e pelo exército. Foi através da inserção dos países colonialistas nos países tropicais, que a Geografia Médica se desenvolveu com maior afinco, principalmente pela produção de informações sobre medidas preventivas a serem tomadas pelos colonizadores e pelos exércitos, "a aproximação entre o saber médico e a geografia só foi impulsionada a partir do século XVI com os grandes descobrimentos, que colocaram a necessidade de se conhecer as doenças nas terras conquistadas, visando à proteção de seus colonizadores e ao desenvolvimento das atividades comerciais" (COSTA; TEIXEIRA, 1999, p. 273)

Segundo Junqueira (2009), o método positivista trouxe uma aproximação dos médicos com a matemática, que acreditavam que o ambiente poderia ser normatizado através de leis específicas. Destacou-se, neste período, que a ideia de que o resultado do domínio da natureza pelo homem seria a conquista das doenças buscando o seu controle preventivo. Porém, as morbidades eram calculadas levando-se em conta os climas quentes e frios.

Neste período, houve uma relação mais estreita entre Geografia e Epidemiologia, o que resultou em estudos importantes para a Geografia Médica. Os estudos gerados através dessa aproximação produziram documentos cartográficos detalhados, principalmente da distribuição minuciosa regional das doenças (VIEITES; FREITAS, 2001). Estas espacializações seriam encontradas nos estudos de topografias médicas, porém as descrições imperavam e não se tinha uma análise crítica acerca do assunto. Os médicos atribuíam as causas das doenças ao ambiente físico, ou seja, o solo, o relevo, a vegetação e principalmente ao clima, por não conhecerem ainda os agentes etiológicos e microbianos das doenças. Destaca-se então, uma visão determinística de causa e efeito (PEITER, 2005).

É possível verificar neste período, a elaboração dos atlas de Geografia Médica em meados do século XIX, que foram importantes,pois orientavam as 
obras de saneamento ambiental "e, especialmente, fundamentavam medidas preventivas a serem tomadas pelos exércitos europeus em caso de ocupação militar de territórios insalubres do mundo tropical" (FERREIRA, 1991, p. 303).

Cabe ressaltar que, quando se passa a confrontar as relações entre fenômenos biológicos e sociais, inicia-se um novo paradigma para se interpretar o problema teórico e prático dessas relações. Surge aqui, portanto, a noção de causalidade sobre essas relações buscando-se construir uma base teórica mais solidificada, elencando a relação do biológico com a sociedade.

Os primeiros estudos de aproximação da Geografia Médica com a Epidemiologia resultaram em análises metodológicas empregadas principalmente pela cartografia e pela bioestatística. Entretanto, uma parte importante para a consolidação destes estudos, não foram contemplados os conceitos para uma inter-relação mais efetiva dessas ciências, "desta aproximação inicial surgem trabalhos de caráter descritivo, que se ocupam em estudar padrões de distribuição regional das doenças" (FERREIRA, 1991, p. 304).

No final do século XIX que, Moris Pasteur e Robert Koch revolucionaram, de certa forma, o conhecimento da medicina, quando descobriram as bactérias e os parasitas, criando a denominada revolução bacteriológica. Esse descobrimento reformulou a concepção do processo saúde-doença. Para os estudos de Geografia Médica, essa teoria não foi benéfica, pois a medicina passou a dedicar seus estudos e pesquisas ao corpo humano, deixando assim, de se ter a visão da saúde-doença como uma inter-relação do próprio ambiente.

Dois conceitos desenvolvidos no século $X X$, foram de suma importância para consolidar a relação entre Geografia e Epidemiologia: a Teoria dos Focos Naturais das Doenças Humanas (apresentada por Pavlovsky) e o Complexo Patogênico (desenvolvida por Maximilian Sorre).

O parasitologista Pavlovsky, em sua obra "A Teoria dos Focos Naturais das Doenças Humanas", apresentada em 1939 à Academia de Ciências da URSS, estabelece a denominada Tríade Ecológica, em que se destaca o homemagente-ambiente. Esses apontamentos fizeram com que surgissem novamente, a aproximação da relação saúde-doença para o escopo ambiental, definiu-se, portanto, importantes conceitos destacando-se o de "circulação do agente no meio natural" e o da "formação do complexo agente-ambiente (PEITER, 2005; LIMA NETO, 2000).

Durante aproximadamente trinta anos, este conceito auxiliou estudos relacionados aos impactos epidemiológicos decorrentes de formas de uso e ocupação do espaço pelo homem, destacando a abordagem ecológica e epidemiológica. A inovação trazida por Pavlovsky está no conjunto de ideias baseadas não somente em estudos de gabinete, mas principalmente para estudos de campo.

Na França, em 1943, o geógrafo Maximilian Sorre lança o primeiro volume de uma série de três, "Les Fondements de la Géographie Humaine" dando destaque, principalmente,aos fatores biológicos. Sua maior preocupação era oferecer um aparato teórico-metodológico e conceitual para que a Geografia Médica pudesse utilizá-los para fins de estudos interdisciplinares, em que a correlação dos elementos era o ponto central da proposta. O conceito de Sorre possui semelhança com o conceito desenvolvido por Pavlovsky, devido adotarem 
o mesmo princípio de interpretação da relação homem-meio, baseado na ecologia.

No Brasil, o conceito de Pavlovsky teve maior evidência, pois foi divulgado com magnitude pela escola de epidemiologia brasileira, tendo Samuel Barnsley Pessôa, seu maior estudioso e divulgador. Já o conceito de Sorre, em um primeiro momento, não foi propagado com intensidade pela academia brasileira. Porém, no campo da geografia, os trabalhos de Max. Sorre tiveram maior aceitação, sendo suas publicações consideradas por vários pesquisadores como uma obra prima do século $\mathrm{XX}$, principalmente por interrelacionar a geografia com as ciências sociais e biológicas. A busca por essa inter-relação marcou a obra de Sorre, pois o conceito de Complexo Patogênico tem como ponto central a relação do homem com o meio em que vive, ou seja, seu habitat, ampliando o poder da análise geográfica, outrora descritiva.

O Complexo Patogênico, enquanto referência, possuía uma afinidade direta com a possibilidade da relação homem-meio em afetar a saúde humana, dando destaque para as doenças infecciosas e parasitárias. Essa interferência, segundo Sorre, poderia impactar no cotidiano da população, levando a uma menor expectativa de vida e disseminação de doenças transmissíveis.

Aliás, toda sua formulação conceitual partiu das doenças infecciosas e parasitárias,que tinham evidência em meados do século $X X$, como pode ser observado nos dizeres de Sorre,

Na complexidade das relações que interessam a uma só vez ao biólogo e ao médico, procura-se uma noção sintética capaz, de orientar as pesquisas do geógrafo. A interdependência dos organismos postos em jogo na produção de uma mesma doença infecciosa permite inferir uma unidade biológica de ordem superior: o complexo patogênico. Compreende, além do homem e do agente causal da doença, seus vetores e todos os seres que condicionam ou comprometem sua existência. (...) Tendo por base esta noção é que nos propomos afundar o capítulo mais vasto da geografia médica, o das doenças infecciosas; sem ela, este nada seria senão uma coleção de fatos desprovidos de ligação e de alcance científico (SORRE, 1951, p. 15).

Os complexos patogênicos de Sorre recebiam o nome das doenças de referência dos estudos, tais como, por exemplo, o complexo malárico. Esses complexos não possuíam números reduzidos de aspectos a serem analisados, mas sim, uma análise integrada de todos os elementos possíveis, configurandose em uma análise epidemiológica evolutiva, que tinha sua origem, seu desenvolvimento e sua estagnação ou desaparecimento. O homem não é visto simplesmente como hospedeiro das doenças, mas sim, como agente transformador do espaço e como possível agravador de determinadas enfermidades.

Em sua obra, Sorre destaca três complexos patogênicos: oda malária, doença do sono e da peste. No capítulo que é dedicado à Geografia Médica do mediterrâneo, são abordados uma gama de dados e informações biológicas e geográficas, destacando a importância do clima na ação dos complexos patológicos, além do uso da cartografia como forma de espacializar essas 
doenças. Pode-se afirmar, que essa é a grande diferença dos estudos produzidos por Sorre em relação aos de Pavlovsky, que produziu apenas estudos relacionados à transmissão ao homem, pelos animais.

Vários trabalhos foram produzidos baseados em Sorre e sob a égide da Geografia Médica, em que se destacavam estudos relacionados à espacialização das doenças e sua inter-relação com os fatores do meio físico (LIMA NETO, 2000; PARAGUASSU-CHAVES, 2001; COSTA, TEIXEIRA, 1999; VIEITES; FREITAS, 2001; PASCOALINO, 2013).

Nas primeiras décadas do século XX, ocorreu uma mudança significativa da ciência em relação à origem das doenças. A evolução da ciência remeteu a conhecimentos relacionados aos parasitas e bactérias, passando para segundo plano, os princípios hipocráticos. Esses conhecimentos fizeram surgir uma nova concepção ecológica dos agentes agressores ao organismo humano.

O posicionamento científico de Sorre, utilizando os princípios bioclimáticos, não consistiu apenas na elaboração de sua teoria dos complexos patogênicos, isso não era novidade, pois vários cientistas já tinham mencionado em seus trabalhos o processo saúde/doença através do uso da ecologia. Mas, na forma de se pensar o modo de influência da variação atmosférica na saúde, configurando-se uma nova visão paradigmática.

Destacou-se, nesse paradigma, um olhar mais acurado sobre as variações atmosféricas, em que se evidenciou a necessidade de se entender o ambiente atmosférico como uma configuração de elementos do tempo meteorológico, não buscando somente o estudo da atmosfera simplesmente pela média estatística. Esse estudo do tempo busca a variação do tempo dia-adia, o que certamente resultará em efeitos biológicos e fisiológicos diversos. Sorre destaca também, a magnitude dessas variações sobre a saúde humana.

Nesse contexto, a partir da evolução teórico-conceitual da Geografia Médica, principalmente em função da interferência dos fatores do meio físico no agravamento das doenças, é que surge a Climatologia Médica, apresentando como finalidade compreender a relação dos tipos de tempo com a sua influência no agravamento das doenças em diferentes espaços geográficos.

O termo Climatologia Médica foi usado pela primeira vez por Dorno, em um Congresso Climático ocorrido em Davos (Suíça), em 1925. Contudo, nesta época essa ciência que acabara de nascer enquanto conceitos tinha uma visão mais pontual, cujos principais estudos estavam relacionados ao efeito da radiação solar sobre os animais e vegetais (DORNO, 1933 apud ANNES DIAS, 1946). Este, torna-se fundamental para os estudos geográficos, pelo fato de não abarcar somente os organismos animais e vegetais, mas sim, um âmbito do espaço geográfico em que o número de inter-relações é mais significativo, como pode-se analisar a influência dos fatores atmosféricos (de forma integrada) sobre a fisiologia humana.

Esses fatores estão envolvidos com a relação saúde/doença desde a antiguidade, porém carentes de experimentações e comprovações. A busca de conhecimento com outras ciências (biologia, fisiologia, patologia e epidemiologia) foi de suma importância para o seu destaque no meio acadêmico (HEINLEIN, 2011).

No início do século XX, Humboldt destacava que "todas as variações atmosféricas afetavam sensivelmente os nossos órgãos, reconhecendo o poder 
de influenciar os sentidos e os estados d'alma do homem". Embora esses dizeres sejam simplistas, sem dúvidas, já indicavam o caminho que iria ser tomado pela Climatologia Médica.

Neste período, as pesquisas em Climatologia Médica destacavam-se pelos estudos da influência da radiação solar na temperatura da pele, ou seja, seu poder refrigerante e secante, começando a ser trabalhado com maior intensidade o conceito de conforto térmico.

Estes estudos se confundiam com os da Biometeorologia e até mesmo com a própria Geografia Médica, na qual se insere, e pelas correlações intrínsecas que as mesmas possuem. Todavia, o que vai diferenciar a Climatologia Médica das demais é seu caráter antropocêntrico e de maior aplicabilidade, destacando as afinidades entre a fisiologia humana e os elementos climáticos (LACAZ, 1972). Neste contexto, se evidencia o domínio da ecologia humana e da Climatologia Médica, ciências que são de interesse peculiar aos Geógrafos, Biólogos e Médicos (SORRE, 1951).

Segundo Philiphoneau (1966), as pesquisas que abordam a Climatologia Médica possuem caráter preventivo como também curativo, além de se evidenciar nos estudos de adaptabilidade climática, a busca de uma amenização das interferências climáticas na fisiologia humana.

Conforme Annes-Dias (1946) a tentativa de se apontar a relação entre o clima ou os diferentes tipos de tempo e as patologias de forma geral, é bastante antiga. Ao se destacar à bibliografia médica produzida no passado, encontra-se alguns elementos tais como: a pressão barométrica, nebulosidade, umidade do ar, pluviosidade e, principalmente a radiação e sua influência no surgimento e agravamento das doenças. Destaque também deve ser dado, às estações do ano e seus efeitos nas patologias sazonais. Nos dizeres de Hipócrates "todas as doenças nascem em todas as estações, mas algumas, em certas estações nascem e se exacerbam de preferência".

Neste contexto, evidencia-se que a Climatologia Médica não é uma disciplina isolada, nem mesmo pertence à climatologia, ela é sim uma ciência cujo papel principal é de auxiliar médicos, epidemiologistas e gestores públicos, bem como em questões de saúde pública, estudos sobre a influência dos diversos fatores atmosféricos no cotidiano da população com ênfase no processo saúde/doença. Os pesquisadores que se dedicam a essa ciência, devem sempre acompanhar pesquisas e estudos sobre patologias e o desenvolvimento e evolução da epidemiologia.

É inegável a ação do clima ou dos tipos de tempo sobre o homem, porém o que alguns contestam é a incapacidade do homem em se adaptar aos eventos extremos do clima, mantendo todas as suas capacidades biológicas, ou seja, sua saúde física e mental.

Parte-se do princípio de que um organismo sadio possui mais probabilidade de se adaptar, em relação às variações dos tipos de tempo e do clima. Contudo, indivíduos sensíveis (à pressão atmosférica, temperaturas, umidade relativa do ar, etc.) ou doentes, não possuem a capacidade de adaptação tão eficaz, apresentando dificuldade em manter-se em estado de equilíbrio. Isso ocorre, devido ao comprometimento do aparelho regulatório, como por exemplo, é observado em indivíduos que possuem doenças cardíacas ecrônicas, diabéticos e hipertensos. 
No contexto atual, diversos pesquisadores de diferentes formações (Médicos, Biólogos, Matemáticos, Meteorologistas, Estatísticos e Geógrafos) tem-se debruçado em pesquisas no intuito de se desvendar as relações reais ou suspeitas, a respeito do tempo e o início da doença. O papel do Geógrafo, em relação à Climatologia Médica é principalmente de cunho etiológico e pretendem estabelecer uma base metodológico-conceitual de correlações entre dados climáticos e de saúde (BESANCENOT, 1986).

Identificar as causas das doenças foge à competência do Geógrafo, entretanto deve-se evidenciar sua habilidade para se compreender a correlação dos fenômenos atmosféricos, principalmente os tipos de tempo e sua influência na saúde do ser humano, se atendo para não perder sua identidade e cair em descrédito. Enquanto o Médico se ocupa das causalidades das doenças, o Geógrafo se preocupa com a sua etiologia, buscando demonstrar como os diferentes tipos de tempo e de clima levam ao agravamento de patologias diversas.

Besancenot (1986) destacou em seus estudos, os fatos de que por um lado, as temperaturas extremas podem resultar em elevada mortalidade em um curto período de tempo, por outro as variações climáticas imprimem em determinadas doenças um ritmo sazonal conforme sua localidade. Essa característica é reconhecida em algumas doenças cardiovasculares como Infarto do Miocárdio (STEWART et al., 2002) e o Acidente Vascular Cerebral (LAAID et al., 2004; GOGGINS et al., 2011).

Este tipo de abordagem foi escolhido para ser trabalhado,tratando sobre os Acidentes Vasculares Cerebrais (AVC) e o Infarto do Miocárdio, doenças do sistema circulatório e que são influenciadas pelos tipos de tempo e clima. $O$ intuito foi de conhecer principalmente a influência das temperaturas mínimas no agravamento das doenças circulatórias, sem deixar de lado é claro, os fatores fisiológicos.

As temperaturas frias são destacadas por diferentes autores, como uma condição térmica para o agravamento de morbidade e mortalidade por doenças do grupo cardiovascular, principalmente em regiões europeias. Nas regiões tropicais, determinadas pesquisas embora ainda em ascendência, indicam que o desconforto térmico para temperaturas frias e altas amplitudes térmicas e até mesmo amplitudes higrométricas (SILVA, 2010), destacando os tipos de tempo no inverno (PITTON e DOMINGOS, 2004; MURARA, COELHO e AMORIM, 2010; PASCOALINO, 2012), resultam no aumento e no agravamento da morbidade e até mesmo na mortalidade por doenças cardiovasculares.

Evidenciam-se também, a importância dos fatores hereditários, hábitos de consumo e modo de vida, como fatores influenciadores de enfermidades. A variação térmica é apenas um destes fatores que podem interferir na relação saúde/doença dos organismos. As temperaturas baixas podem desestabilizar os mecanismos termorreguladores, fazendo com que ocasione um estresse fisiológico, principalmente em indivíduos debilitados (com obesidade mórbida, diabetes, hipertensivos, dentre outros).

Compreender em quais condições ambientais ocorrem o agravamento da morbidade e mortalidade, é um fator primordial para os gestores da saúde, principalmente para a promoção da saúde e não somente atacando o tratamento das doenças. Neste contexto, entender os padrões existentes, no 
contexto térmico se torna uma condição sine qua non para a promoção da saúde.

\section{PROCEDIMENTOS METODOLÓGICOS}

Para se compreender a influência dos tipos de tempo atmosférico no agravamento das doenças cardiovasculares, realizou-se primeiramente, a compilação dos dados climáticos (temperatura mínima e umidade relativa do ar) com o intuito de identificar as ondas de frio.

Para a construção do conceito de onda de frio utilizou-se o percentil 5 como parâmetro. Este cálculo possibilitou encontrar a temperatura mínima de $11,3^{\circ}$ C. Portanto, determinou-se que uma onda de frio para a região do Pontal, seria três dias ou mais consecutivos de temperatura mínima abaixo do percentil $5\left(11,3^{\circ} \mathrm{C}\right)$. Embora essa região seja marcada constantemente por temperaturas altas, consequentemente, devido a entrada da Massa Polar Atlântica pelo continente, essas temperaturas apresentam quedas significativas.

Os dados (horários) coletados abarcaram um universo de 10 anos (2008 a 2017). Para se compreender a espacialização e duração das ondas de frio, foram coletados dados de seis estações meteorológicas pertencentes ao Instituto Nacional de Meteorologia (INMET), sendo estas: Ituiutaba - MG; Capinópolis - MG; Campina Verde - MG; Itumbiara - GO; São Simão - GO e Paranaíba - MS.

Os dados de internações por Infarto Agudo do Miocárdio foram fornecidos pelas Secretarias Municipais de Saúde e pelo Corpo de Bombeiros. Estes dados também foram obtidos para o mesmo período. Destaca-se aqui, que a escala temporal escolhida para a presente pesquisa foi diária, sendo compatível com os dados climáticos e essenciais para os estudos mais detalhados.

Utilizando-se os dados climáticos e de internações, foi possível confeccionar gráficos (através do Software Microsoft Excel) que foram de suma importância para a análise espacial dos dados concomitantes, sendo possível definir as ondas de frio e os índices de internações por Infarto Agudo do Miocárdio da população da região do Pontal do Triângulo Mineiro. Para a validação dos dados, foi utilizado o Coeficiente de Correlação Linear de Pearson. Foram mapeadas 12 ondas de frio no decorrer dos 10 anos de estudo, entretanto, nesta presente pesquisa foram trabalhadas apenas quatro, visando uma análise mais aprofundada dos dados. Deste modo, escolheu-se as quatro ondas de frio mais intensas no intervalo estudado.

Para a Correlação de Pearson utilizou-se como referência os parâmetros desenvolvidos por Cohen (1988) citado por Figueiredo Filho e Silva Júnior (2009, p. 119), sendo "os valores entre 0,10 a 0,29 podem ser considerados pequenos; escores entre 0,30 a 0,49 podem ser considerados como médios; e valores entre 0,50 a 1 podem ser considerados como grandes".

Os sistemas atmosféricos atuantes foram verificados de acordo com a análise de imagens de satélite e cartas sinóticas de superfície, pertencentes ao Instituto Nacional de Pesquisas Espaciais (INPE), objetivando-se analisar sua influência sobre a queda das temperaturas nos períodos estudados sobre a região do Pontal do Triângulo Mineiro. 
Para a confecção dos mapas utilizou-se a média simples das temperaturas mínimas durante cada período das ondas de frio. A partir disto foi elaborada a triangulação dos pontos de coleta dos dados (estações meteorológicas). O Software QGis3.2.1 foi a ferramenta utilizada para a produção dos referidos mapas.

\section{AS ONDAS DE FRIO E A SAÚdE HUMANA NA REGIÃO DO PONTAL DO TRIÂNGULO MINEIRO}

A compreensão da dinâmica dos sistemas atmosféricos atuantes em uma determinada área, são de suma importância para tentar explicar a influência dos tipos de tempo e sua relação com o agravamento das doenças cardiovasculares. Assim, cada sistema corresponde a um ciclo (VASCONCELOS; ZAMPARONI, 2010).

Segundo Ribeiro (1975, p.29), os sistemas atmosféricos mostram, no decorrer dos dias, variações subordinadas a fatores que regem a circulação geral da atmosfera. Portanto, a duração e a intensidade dos centros de ação e frentes correlacionam-se, principalmente, ao mecanismo gerador das estações do ano conferindo-lhes um determinado regime de força e duração de acordo com a sazonalidade.

No caso da região do Pontal do Triângulo Mineiro tem-se um fator importante que influencia a circulação geral da atmosfera, principalmente facilitando o deslocamento da Massa Polar Atlântica, que é a conformação do relevo. A região se localiza entre dois rios de grande porte, o Rio Paranaíba e o Rio Grande. O vale do Paranaíba é bem encaixado facilitando o deslocamento da massa polar e afetando diretamente a porção norte da região do Pontal do Triângulo (Figura 2).

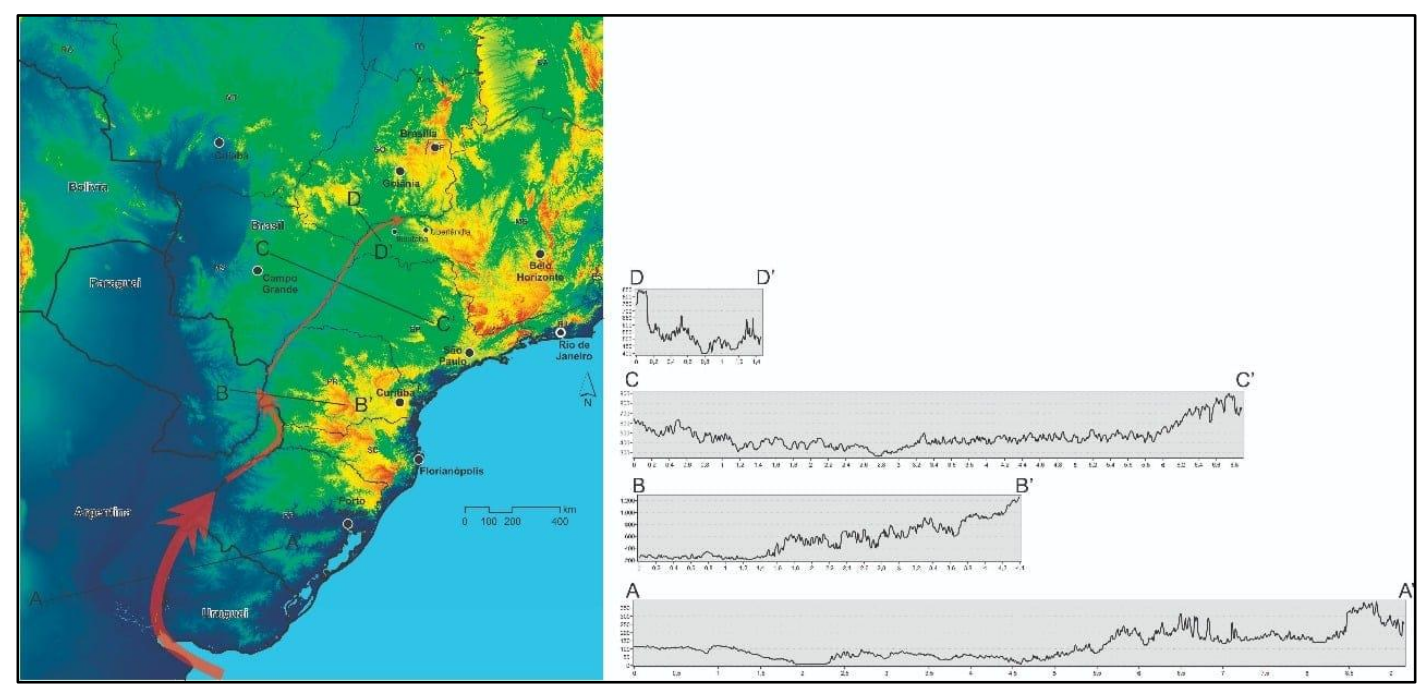

Figura 2 - Perfis Topográficos do Vale do Rio Paraná. Org.: Costa e Allan-Silva (2018).

Observa-se, portanto, que quando a Massa Polar entra na América do Sul, de forma continental, o caminho que ela percorre fica facilitado pelo vale 
dos rios. Isso faz com que a porção noroeste-norte da região se resfrie mais do que as outras, devido ao encaixe do vale do Paranaíba e dos Rios Tijuco e da Prata, fazendo principalmente a cidade de Ituiutaba, registrar temperaturas muito baixas. Cidade esta, que é conhecida justamente por suas temperaturas altas durante grande parte do ano.

Portanto, esta condição geomorfológica aliada ao deslocamento da massa polar, se torna uma condição sine qua non para que as ondas de frio ocorram na região do Pontal do Triângulo Mineiro. A seguir, serão caracterizadas as ondas de frio mapeadas na região.

\section{ANÁLISE DA ONDA DE FRIO DE MAIO DE 2010}

O mês de maio de 2010 destacou-se como um dos mais frios dos últimos 20 anos na região, este processo fez surgir uma das maiores ondas de frio que durou aproximadamente 15 dias (09 a 24 de maio). Os vales do Rio Tijuco e da Prata, onde se localizam a cidade de Ituiutaba e Gurinhatã, respectivamente, obtiveram a temperatura mais baixa $\left(3,4^{\circ} \mathrm{C}\right)$, como pode ser observado no gráfico 2. A Massa Polar, neste período, teve uma entrada continental acentuada, criando esse cenário para a região do Pontal do Triângulo Mineiro.

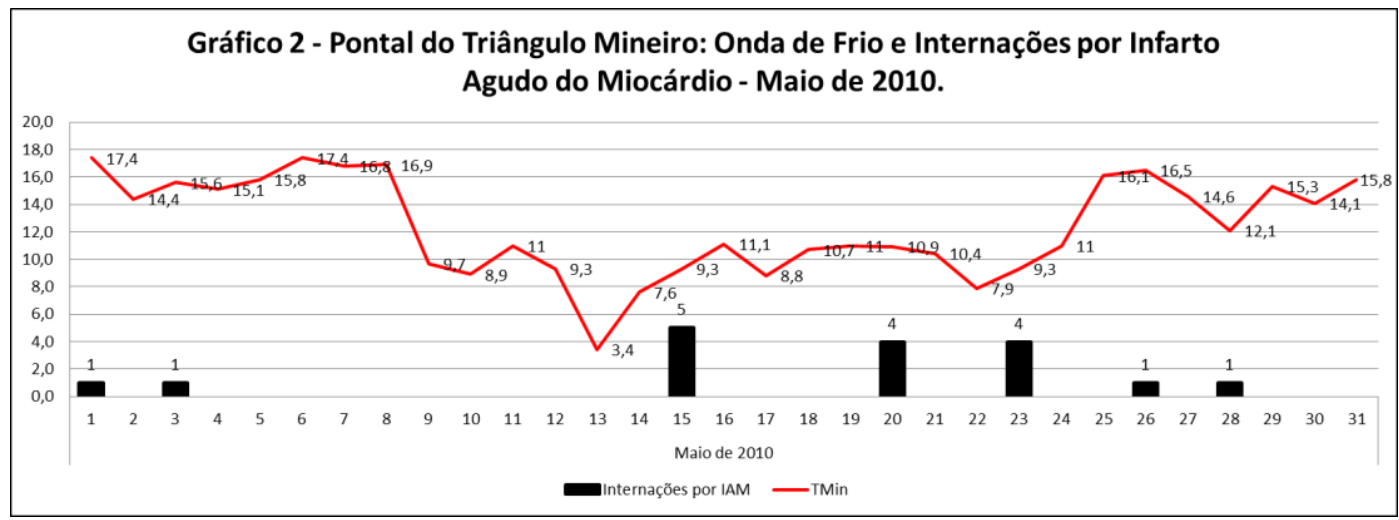

Gráfico 2 - Pontal do Triângulo Mineiro: Onda de Frio e Internações por Infarot Agudo do Miocárdio - Maio de 2010. Fonte: INMET e Secretarias Municipais de Saúde da Região do Pontal. Org.: Costa (2018).

Outro fator evidente foi a amplitude térmica, que teve uma média de $19,8^{\circ} \mathrm{C}$ durante o evento. A temperatura máxima da pré-frontal (um dia antes do evento se iniciar) foi de $33,5^{\circ} \mathrm{C}$, ou seja, em aproximadamente 24 horas ocorreu uma queda brusca de temperatura de $23,8^{\circ} \mathrm{C}$, sendo significativa para a região.

Essa dinâmica atmosférica se mostrou nociva para a saúde das pessoas, principalmente para os idosos, que são mais vulneráveis a essa condição de tempo. Neste período foram contabilizadas 17 internações, com destaque para 13 casos durante o evento da onda de frio. O mês de maio possui, segundo dados das Secretarias Municipais de Saúde, uma média de internações por Infarto Agudo do Miocárdio de 5,3 casos. Portanto, um aumento de mais de 
$200 \%$ de casos. Analisando todos os meses de maio, somente o de 2010 apresentou esse crescimento, demonstrando a influência da onda de frio no fluxo das internações. Ao utilizar a correlação de Pearson para validar os dados, observou-se que a mesma foi alta $(0,8628)$.

A figura abaixo (figura 3) corroborou com a análise da onda de frio, em que o vale do Rio Paranaíba foi a área mais fria da região, atingindo as cidades de Carneirinho, Limeira do Oeste, Santa Vitoria, Ipiaçu, Capinópolis, Cachoeira Dourada, Gurinhatã e Ituiutaba, está ultima sofrendo mais com as temperaturas baixas, devido sua localização no vale do Rio Tijuco, que é afluente do Rio Paranaíba.
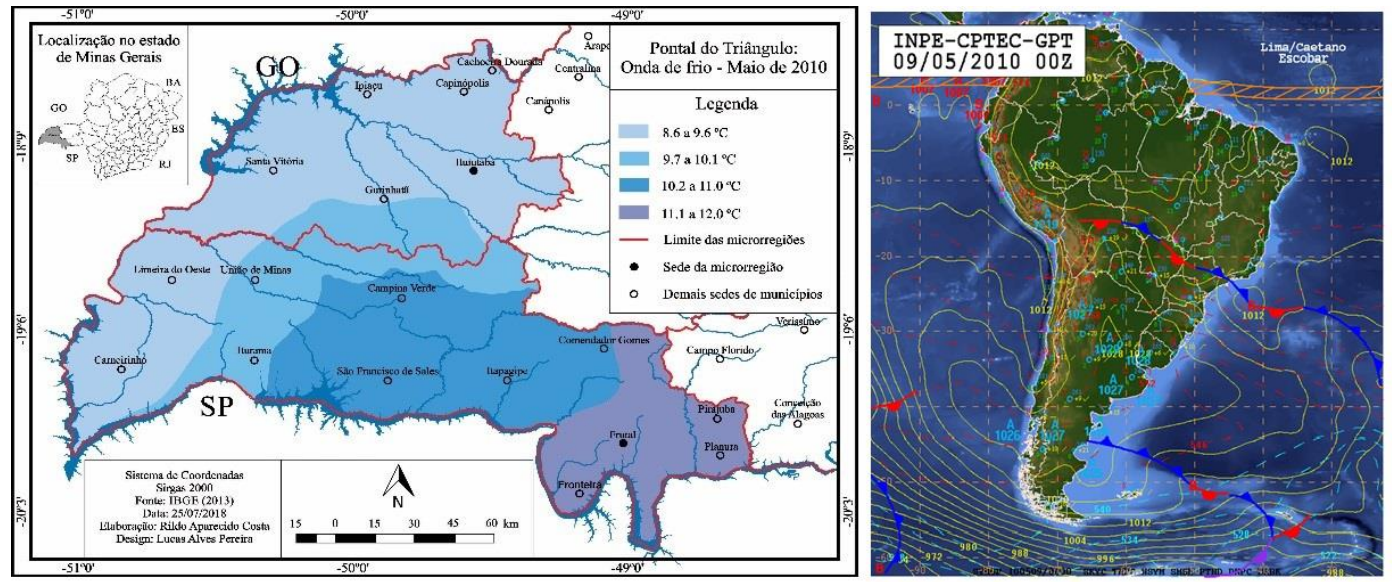

Figura 3 - Mapa representativo da onda de frio e carta sinótica de maio de 2010. Org.: Costa (2018).

Analisando a carta sinótica do dia nove de maio de 2010, observou-se que a Massa Polar está estacionada na borda sul da região do Pontal do Triângulo Mineiro. Sua entrada pelo vale dos rios foi tão intensa que causou o fenômeno de friagem na região amazônica. Esse sistema fez com que a região registrasse temperaturas muito baixas por vários dias.

Em suma, essa condição atmosférica causada pela atuação deste sistema fez com que as cidades sofressem com uma friagem intensa, afetando diretamente a saúde dos indivíduos que se acostumaram com temperaturas constantemente altas e foram acometidas por essa onda de frio intensa.

\section{ANÁLISE DA ONDA DE FRIO DE JULHO DE 2012}

Esta onda de frio ocorreu entre os dias 14 e 21 de julho de 2012, com uma duração de oito dias (gráfico 3). Novamente, a temperatura mais baixa ocorreu no vale do Rio Tijuco $\left(3,8^{\circ} \mathrm{C}\right)$, sendo Ituiutaba a cidade mais fria. Essa condição se explica por Ituiutaba se localizar no vale do Rio Tijuco, um corredor importante para a entrada da Massa Polar. Vale destacar também, a amplitude térmica média durante os dias da onda de frio para a região, que atingiu $17,3^{\circ} \mathrm{C}$. 


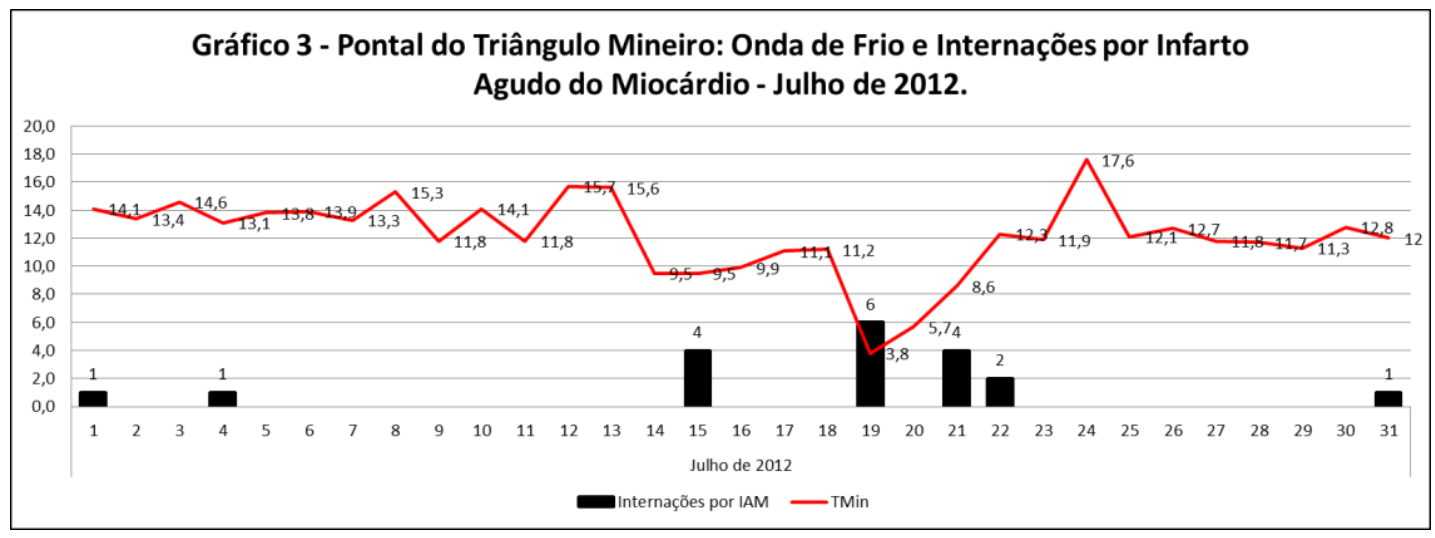

Gráfico 3 - Pontal do Triângulo Mineiro: Onda de Frio e Internações por Infarto Agudo do Miocárdio - Julho de 2012. Fonte: INMET e Secretarias Municipais de Saúde da Região do Pontal. Org.: Costa (2018).

Outro fator importante foi a temperatura máxima (pré-frontal) um dia antes do início da onda, que foi de $29,7^{\circ} \mathrm{C}$, tendo uma queda em 24 horas de aproximadamente $20^{\circ} \mathrm{C}$, sendo significativo para a região, principalmente quando se trata de influenciar a saúde da população. Ao utilizar a correlação de Pearson para validar os dados, observou-se que a mesma foi alta $(0,8921)$.

Foram registradas, segundo dados das Secretarias Municipais de Saúde, 19 internações por Infarto Agudo do Miocárdio. É importante destacar, que a média para o mês de julho é de 6,3 internações, ou seja, houve um aumento de mais de $200 \%$ no número de casos que se concentraram entre os dias 15 e 22 (16 internações), justamente no período de ocorrência da onda de frio.

Em relação à figura 4, observou-se que a temperatura mais baixa da onda de frio ocorreu no vale do Rio Paranaíba, fazendo um corredor desde a cidade de Carneirinho, até a cidade de Ituiutaba, marcando bem o caminho da massa polar pelo vale dos rios.
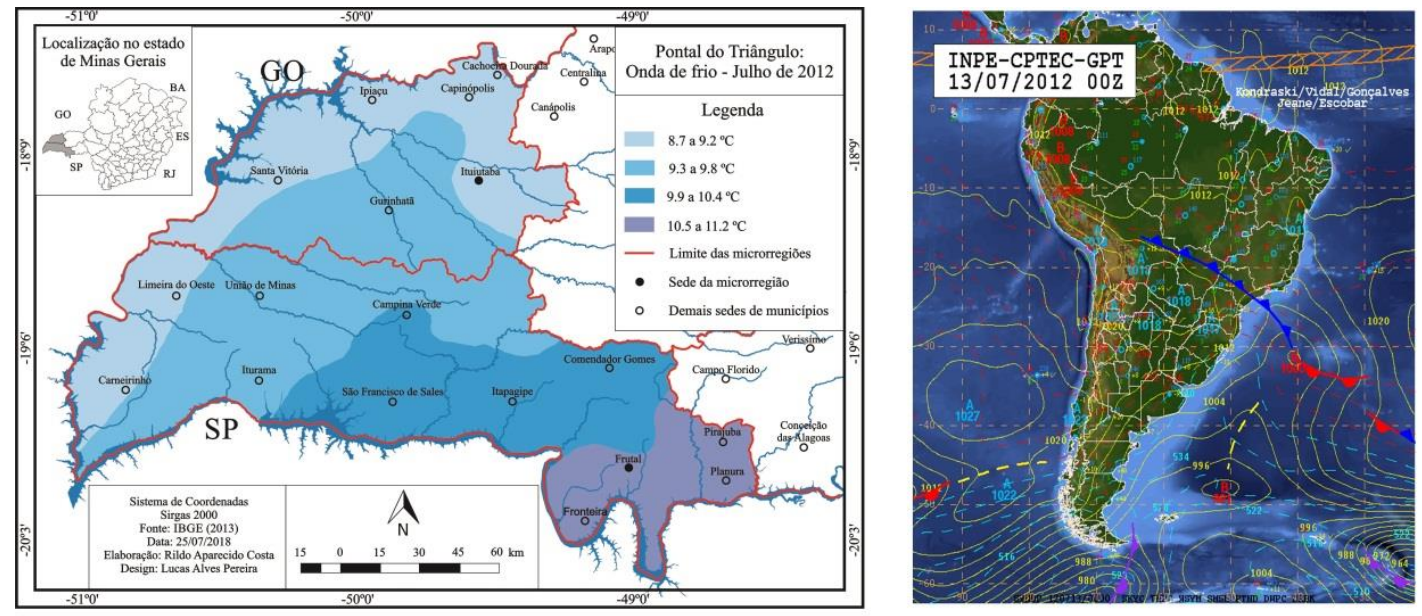

Figura 4 - Mapa representativo da onda de frio e carta sinótica de Julho de 2012. Org.: Costa (2018). 
Outro fator importante durante este mês foi a baixa umidade relativa do ar, que variou entre $16 \%$ a $35 \%$ (umidade mínima). A velocidade do vento também foi um fator preponderante na análise, tendo uma média simples de 27 $\mathrm{km} / \mathrm{h}$, causando uma sensação térmica maior. Essa condição de temperatura baixa, velocidade do vento maior e umidade relativa baixa se torna ideal para o agravamento das doenças cardiovasculares, dentre estas, o Infarto Agudo do Miocárdio.

\section{ANÁLISE DA ONDA DE FRIO DE MAIO DE 2013}

$\mathrm{Na}$ análise da Onda de Frio de Maio de 2013observou-se que esta apresentou uma dimensão temporal de quatro dias (09 a 12 de maio de 2013), sendo o pico mais significativo registrado a $7,6^{\circ} \mathrm{C}$ (gráfico 4 ). 0 vale do Rio Paranaíba foi a área de maior intensidade entre a região do Pontal do Triângulo Mineiro, demostrando o caminho da Massa Polar.

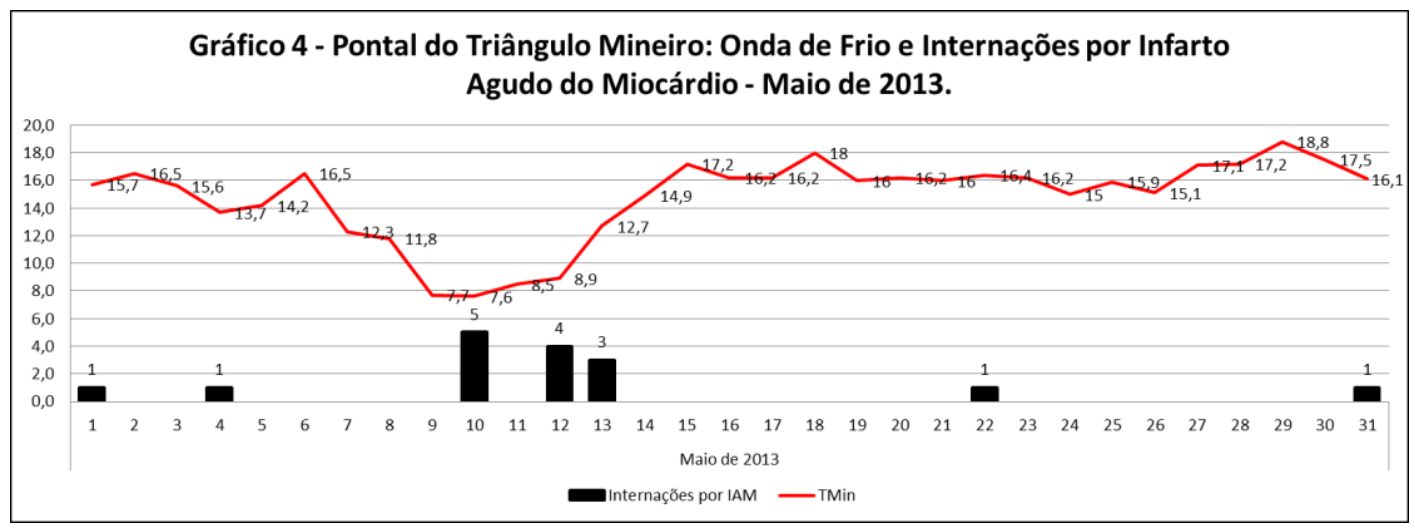

Gráfico 4 - Pontal do Triângulo Mineiro: Onda de Frio e Internações por Infarto Agudo do Miocárdio - Maio de 2013. Fonte: INMET e Secretarias Municipais de Saúde da Região do Pontal. Org.: Costa (2018).

A amplitude térmica média para o período foi de $18,7^{\circ} \mathrm{C}$ e uma temperatura máxima da pré-frontal de $27,9^{\circ} \mathrm{C}$ (dia 8 de maio), com uma queda brusca de temperatura na ordem de $20,2^{\circ} \mathrm{C}$, em aproximadamente 24 horas.

Neste período, contabilizaram-se 16 internações por Infarto Agudo do Miocárdio, sendo 12 destas, concentrando-se no período da onda de frio. A média de internações para o mês em questão é de 5,3 casos. Portanto, nota-se que foi um mês atípico, apresentando um aumento de mais de $250 \%$ nos casos de internação.

Na figura 6, é possível observar novamente, que o vale do Paranaíba registrou as menores temperaturas, sendo as cidades de Ipiaçu e Capinópolis as mais frias da região. Na carta sinótica do dia 08 de maio observou-se um sistema estacionário na região sudeste. Ao utilizar a correlação de Pearson para validar os dados, observou-se que a mesma foi alta $(0,9251)$. 

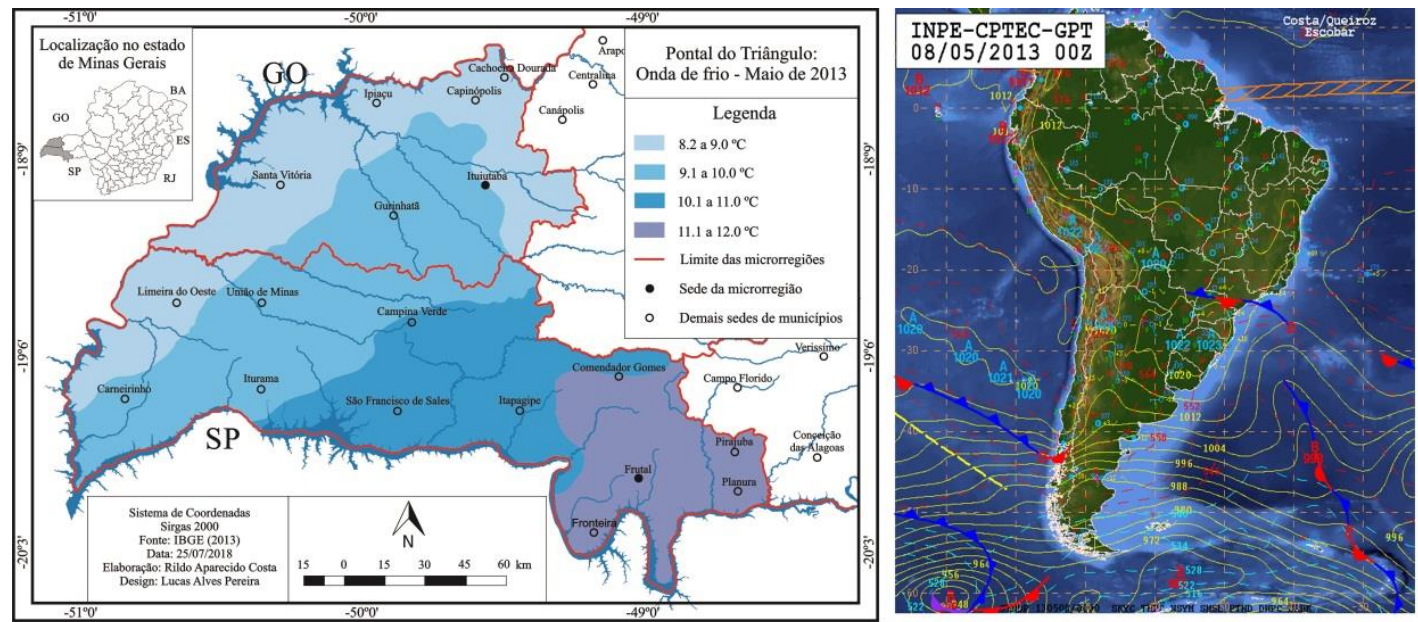

Figura 5 - Mapa representativo da onda de frio e carta sinótica de maio de 2013. Org.: Costa (2018).

Novamente, devido a onda de frio, a região se mostrou com condições ideais para o agravamento das doenças cardiovasculares, causando problemas na região e aumentando o índice de internações.

\section{ANÁLISE DA ONDA DE FRIO DE JULHO DE 2016}

A onda de frio em questão teve uma duração de cinco dias (18 a 23 de julho de 2013), como pode ser observado no gráfico 5 . Observou-se que destacaram dois picos de temperaturas extremas baixas, no dia 13 em que foi registrada uma temperatura de $5,4^{\circ} \mathrm{C}$, mas não se configurou em uma onda de frio, devido ter sido apenas um dia, e no dia 18 (início da onda de frio) de $3,2^{\circ} \mathrm{C}$, sendo a temperatura mais baixa registrada na região do Pontal do Triângulo Mineiro, nos últimos 20 anos.

A amplitude térmica média durante essa onda de frio foi de $22,5^{\circ} \mathrm{C}$ (diferença da maior para a menor temperatura). A temperatura máxima da préfrontal (dia 17 de julho) foi de $34,1^{\circ} \mathrm{C}$, apresentando uma queda de aproximadamente $23^{\circ} \mathrm{C}$ em menos de 24 horas.

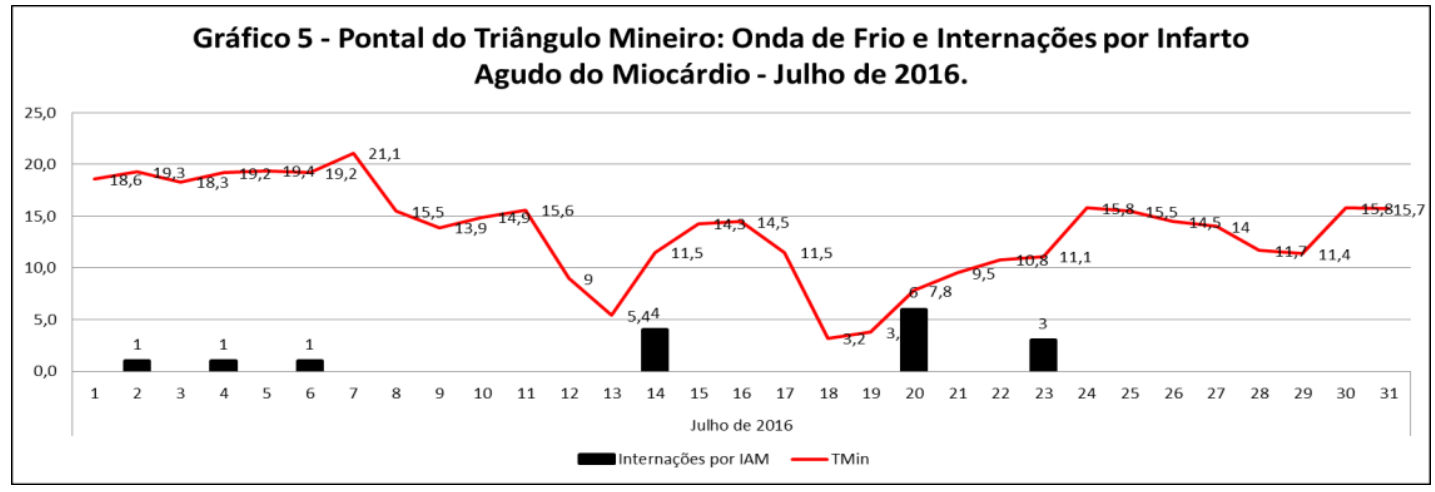

Gráfico 5 - Pontal do Triângulo Mineiro: Onda de Frio e Internações por Infarto Agudo do Miocárdio - Julho de 2016. Fonte: INMET e Secretarias Municipais de Saúde da Região do Pontal. Org.: Costa (2018). 
Neste período,ocorreram 16 internações, sendo que durante a onda de frio foram 09 internações por Infarto Agudo do Miocárdio. A média de internações para o mês de julho é de 6,3 casos. No entanto, neste mês, com a presença da onda de frio verificou-se um aumento considerável de mais de $120 \%$.

Observa-se na figura abaixo, que as temperaturas mais baixas foram registradas no vale do Rio Paranaíba, sendo a cidade de Ituiutaba com o pico mais frio $3,2^{\circ} \mathrm{C}$ (dia 18 de julho). A carta sinótica do dia 17 de julho demonstra um sistema atuando sobre a região do Pontal do Triângulo. Ao utilizar a correlação de Pearson para validar os dados, observou-se que a mesma foi alta $(0,9643)$.
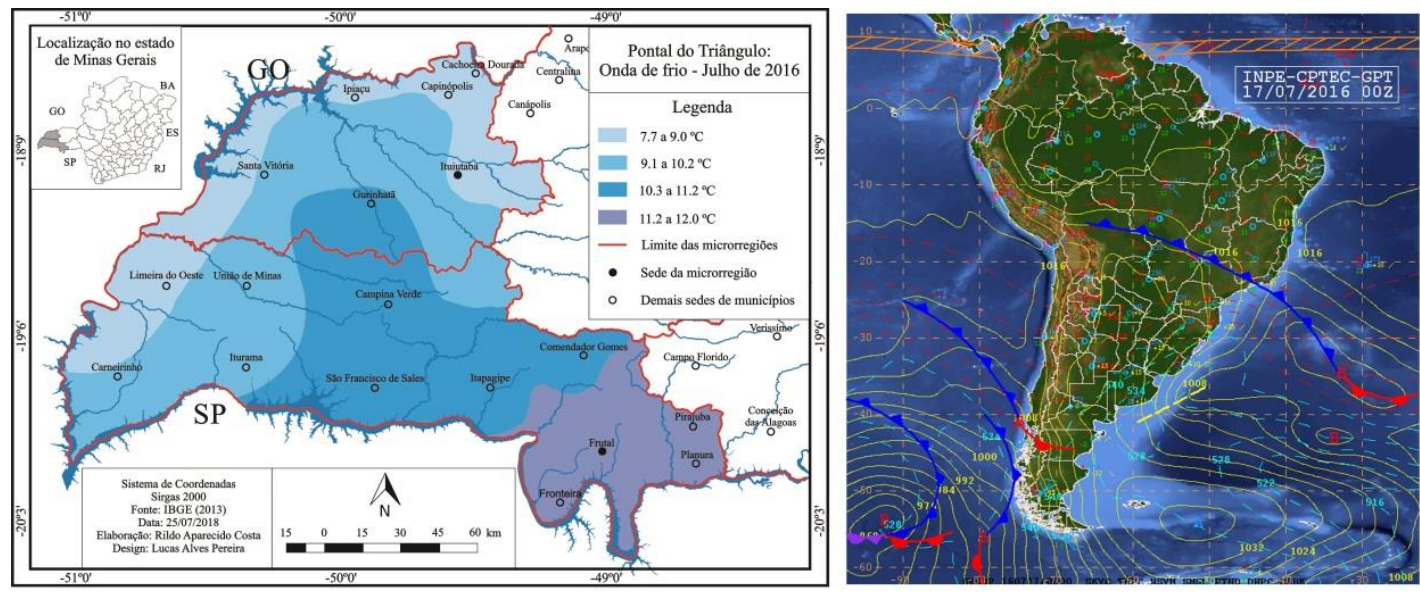

Figura 6 - Mapa representativo da onda de frio e carta sinótica de Julho de 2016. Org.: Costa (2018).

Vale ressaltar, que este sistema atuando, juntamente com uma umidade relativa do ar que variou entre $20 \%$ a $42 \%$ (umidade mínima), aliada a uma velocidade do vento média de $29 \mathrm{~km} / \mathrm{h}$, tornou-se o cenário ideal para a influência na saúde dos indivíduos, agravando o quadro de internações na região do Pontal do Triângulo Mineiro.

\section{CONSIDERAÇÕES FINAIS}

Conforme o objetivo proposto, pela pesquisa, observou-se que as ondas de frio que ocorreram na região do Pontal do Triângulo Mineiro, podem ter influenciado no aumento de internações por Infarto Agudo do Miocárdio. É importante ressaltar que, além das influências que o tempo atmosférico pode exercer sobre os indivíduos, existem outras variáveis que contribuem para o agravamento das doenças cardiocirculatórias, tais como o funcionamento fisiológico, comportamento alimentar, genética e perfil socioeconômico, dentre outras.

A análise dos resultados obtidos possibilitou uma satisfatória relação entre as ondas de frio e o índice de internações por IAM. Observou-se que, das quatro ondas de frio estudadas, duas ocorreram no mês de maio, que é um 
período de transição da estação chuvosa para a estação seca na região estudada e duas no mês de julho, que é a estação seca (também compreendido pela estação de inverno).

O aumento nos índices de internações foi significativo econstantemente acima de $100 \%$, dando destaque para a onda de frio do mês de maio de 2016, em que se teve um aumento de $250 \%$. O mês de julho frequentemente, foi acompanhado por uma umidade relativa do ar baixa que é característica da região estudada, isso faz com que o organismo humano responda negativamente a estas condições atmosféricas, alterando a atividade circulatória ocasionando mudanças abruptas no sistema de termorregulação e do balanço de calor do corpo e, consequentemente, na atividade cardiovascular.

Essa análise permitiu também observar que, para se estabelecer uma relação das enfermidades e variações climáticas, necessário se faz trabalhar em uma escala local buscando dados consistentes e detalhados. Analisou-se com isto, que a relação se apresenta na variação abrupta dos elementos que fazem parte da dinâmica atmosférica. Por isso, a importância de se trabalhar com os dados horários, mesmo que isso demande uma quantidade considerável de dados e que se tenha a necessidade prévia de sua preparação.

Outro aspecto importante é de se trabalhar com os dados extremos, pois o trabalho com as médias esconde prováveis variações. Por isso, neste trabalho não se optou por analisar as médias. Se o trabalho fosse feito analisando-se apenas as médias, seria possível ser abarcada uma maior quantidade de anos, entretanto os resultados poderiam ser insatisfatórios.

A tentativa aqui foi de investigar as inter-relações do tempo meteorológico sobre as internações por Infarto Agudo do Miocárdio. Não se pretendeu trazer neste estudo todas as respostas e questionamentos, mas sim, mostrar que se é possível entender o processo e propor atitudes preventivas sobre este assunto.

\section{REFERÊNCIAS}

AB'SÁBER, A. N. Os domínios morfoclimáticos na América do Sul: primeira aproximação. Geomorfologia, São Paulo, n. 52, p. 1-22, 1977.

ANNES-DIAS, $\mathrm{H}$. Introdução ao Estudo da Meteorologia Clinica. Arquivos Riograndenses de Medicina. Porto Alegre, RS, 1946.

ARMSTRONG, R.W. Medical Geography. In: Advances in Medical Social Science. RUFINI, J.L. (ed.). New York: Gordon and Breach Science Publishers, n.1, 1983. p.167-183.

BESANCENOT, J.P. Infarctus du myocarde, saisons et climats. Revue de géographie de Lyon, v. 61, n. 3, p. 271-281, 1986.

COSTA, M.C.N., TEIXEIRA, M.G.L.C. A Concepção de "Espaço" na Investigação Epidemiológica. Caderno de Saúde Pública, v. 15 n.2. Rio de Janeiro abrjun.1999.

DINIZ, D. S. A "ciência das doenças" e a "arte de curar": trajetórias da medicina hipocrática. 160f. Dissertação (Mestrado em Saúde Coletiva). Instituto de Medicina Social - Universidade do Estado do Rio de Janeiro, 2006. 
FERREIRA, M. U. Epidemiologia e Geografia: o complexo patogênico de Max. Sorre. Cadernos de Saúde Pública, Rio de Janeiro, n. 7, p. 301-309, 1991.

FIGUEIREDO FILHO, D. B.; SILVA JÚNIOR, J. A. Desvendando os mistérios do coeficiente de correlação de Pearson. Revista Política Hoje, Vol. 18, n. 1, 2009.

GOGGINS, W. B. et al. Weather, season, and daily stroke admissions in Hong Kong. International Journal Biometeorology, 2011. Disponível em < http://www.springerlink.com/content/100429/> Acesso em: mar 2017.

HEINLEIN, R. Climat, météo et santé: La météo c'est ce à quoi on s'attend, le climat c'est ce que nous obtenons. Observatoire Régional de la Santé Nord - Pas - de - Calais, France, 2011.

JUNQUEIRA, R. D. Geografia Médica e Geografia da Saúde. Hygeia 5(8):57 - 91, Jun/2009.

LACAZ, C. S.; BASRUZZI, R. G. \& SIQUEIRA, W. Introdução à geografia médica do Brasil. São Paulo: Edgard Blücher/ Edusp, 1972. 568p.

LAAIDI, $K$. et al. Variation saisonnière des accidents vasculaires cérébraux et influence des conditions météorologiques. Rev. Neurol. (Paris), v. 160, n. 3, p. 321-330, 2004.

LIMA NETO, J. E. Geografia e Saúde.Dissertação (Mestrado em Geografia) Departamento de Geografia, Universidade de São Paulo, 272 p. 2000.

MARTINS, R. A. Contágio - História da prevenção das doenças transmissíveis. São Paulo: Moderna, 1997.

MENDES, P. C. \& QUEIROZ, A. T. Caracterização Climática do município de Ituiutaba-MG. In: PORTUGUEZ, A. P.; MOURA, G. G. \& COSTA, R. A. (Org) Geografia do Brasil Central: Enfoques teóricos e particularidades regionais. Uberlândia: Assis Editora, 2011.

MURARA, P. G.; COELHO, M. S. Z. S.; AMORIM, M. C. C. T. Análise da influência meteorológica nas internações por doenças cardiovasculares. Caderno Prudentino de Geografia. n. 32, v. 1, p. 53-65, 2010.

ORGANIZAÇÃO MUNDIAL DE SAÚDE (OMS/WHO). Relatório das Doenças Cardiovasculares. Genebra, Suíça, 2011.

PASCOALINO, A. Variação térmica e a distribuição têmporo-espacial da mortalidade por doenças cardiovasculares na cidade de Limeira/SP. 2013. $283 \mathrm{f}$. Tese (Doutorado) - Universidade Estadual Paulista, Instituto de Geociências e Ciências Exatas, 2013.

PESSOA, S. B. Ensaio Médico-Sociais. Rio de Janeiro: Livraria Editora Guanabara, Koogan S.A., 1960.

PEITER P. A Geografia da Saúde na Faixa de Fronteira Continental do Brasil na Passagem do Milênio.Tese (Doutorado). Programa de Pós-Graduação em Geografia, Universidade Federal do Rio de Janeiro, Rio de Janeiro: 324 p., 2005.

PARAGUASSU-CHAVES, C. A. Geografia médica ou da saúde: espaço e doença na Amazônia Ocidental. Porto Velho: EDUFRO, 2001.

PITTON, S. E. C.; DOMINGOS, A. E. Tempo e doenças: efeitos dos parâmetros climáticos nas crises hipertensivas nos moradores de Santa Gertrudes - SP. Estudos Geográficos, Rio Claro, v. 2 n. 1, p. 75-86, 2004. 
PHILIPHONEAU, M. Geógraphie et action: introducion à la géographie appliquée. Paris: Armand Colin, 1966. 227 p.

RIBEIRO, A. G. O consumo de água em Bauru, SP: o tempo cronológico e o tempo meteorológico aplicado na elaboração de subsídios à previsão de demanda de água. Dissertação (Mestrado em Geografia Física), FFLCH/USP, São Paulo, 1975.

RIBEIRO, H. Saúde Pública e Meio Ambiente: evolução do conhecimento e da prática, alguns aspectos éticos. Saúde e Sociedade, v. 13, n.1, p. 70-80, 2004.

SANT'ANNA NETO, J. L. Da climatologia geográfica à geografia do clima Gênese, paradigmas e aplicações do clima como fenômeno Geográfico. Revista ANPEGE, no 4 (2008). UNESP/Presidente Prudente.

SARTORI, M. G. B. Clima e percepção geográfica - Fundamentos Teóricos à Percepção Climática e à Bioclimatologia Humana. Santa Maria: Editora Palloti. 2014.

Severino, E. A. S. A influência da variação das temperaturas mínimas na mortalidade por doenças circulatórias em Ituiutaba (MG). Dissertação (Mestrado em Geografia), UFU, 2017. 138 f.

SILVA, E. N. Ambientes atmosféricos intraurbanos na cidade de São Paulo e possíveis correlações e doenças dos aparelhos: respiratório e circulatório. 2010. Tese (Doutorado) - Faculdade de Saúde Pública, Universidade de São Paulo. São Paulo, 2010, 215 p.

STEWART, $S$. et al. Heart failure in a cold climate: seasonal variation in heart failure - Related morbidity and mortality. Journal of the American College of Cardiology, v. 39, n. 5, 760-766.

SOUZA, C. G. SANT'ANNA NETO, J. L. Geografia da Saúde e Climatolologia Médica: Ensaios sobre a relação Clima e Vulnerabilidade in Hygeia - HYGEIA Revista Brasileira de Geografia Médica e daSaúde (6):116-126, Jun/2008.

SORRE, M. Les fondements da la Géographie humaine. Tome Premier: Les fondements biologiques. 3 ed. Paris: Armand Colin, 1951.

VIEITES, R. G.; FREITAS, I. A. Pavlovsky e Sorre: duas importantes contribuições à geografia médica. Ateliê Geográfico. Goiás, v. 1, n. 2, p.187201, dez. 2001. 